\title{
AUMC Dosing to Last Concentration Normalized by Weight
}

National Cancer Institute

\section{Source}

National Cancer Institute. AUMC Dosing to Last Concentration Normalized by Weight. NCI Thesaurus. Code C92329.

The area under the moment curve (AUMC) from the time of dosing to the last measurable concentration divided by the weight. 